\title{
The health of people classified as lesbian, gay and bisexual attending family practitioners in London: a controlled study Michael King ${ }^{1}$ and Irwin Nazareth*2
}

Address: ${ }^{1}$ Professor of Primary Care Psychiatry, Department of Mental Health Sciences, Royal Free and University College Medical School, University College London, Royal Free Campus, Rowland Hill Street, London NW3 2PF, UK and 2Professor of Primary Care \& Population Sciences \& Director MRC General Practice Research Framework, Department of Primary Care and Population Sciences, Royal Free and University College Medical School, University College London (UCL), Rowland Hill Street, London NW3 2PF, UK

Email: Michael King - m.king@medsch.ucl.ac.uk; Irwin Nazareth* - i.nazareth@pcps.ucl.ac.uk

* Corresponding author

Published: 08 May 2006

BMC Public Health 2006, 6:127 doi:10.1 186/147|-2458-6-127
Received: 24 October 2005

Accepted: 08 May 2006

This article is available from: http://www.biomedcentral.com/I47I-2458/6/127

(C) 2006 King and Nazareth; licensee BioMed Central Ltd.

This is an Open Access article distributed under the terms of the Creative Commons Attribution License (http://creativecommons.org/licenses/by/2.0), which permits unrestricted use, distribution, and reproduction in any medium, provided the original work is properly cited.

\begin{abstract}
Background: The morbidity of gay, lesbian or bisexual people attending family practice has not been previously assessed. We compared health measures of family practice attendees classified as lesbian, gay and bisexual.

Methods: We conducted a cross-sectional, controlled study conducted in 13 London family practices and compared the responses of 26 lesbian and 85 bisexual classified women, with that of 934 heterosexual classified women and 38 gay and 23 bisexual classified men with that of 373 heterosexual classified men. Our outcomes of interest were: General health questionnaire; CAGE questionnaire; short form 12; smoking status; sexual experiences during childhood; number of sexual partners and sexual function and satisfaction.
\end{abstract}

Results: In comparison to people classified as heterosexuals: men classified as gay reported higher levels of psychological symptoms (OR 2.48, $\mathrm{Cl}$ I.05-5.90); women classified as bisexual were more likely to misuse alcohol (OR 2.73, I.70-4.40); women classified as bisexual (OR 2.53, I.60-4.00) and lesbian (OR 3.I3, I.4I-6.97) and men classified as bisexual (OR 2.48, I,04, 5.86) were more likely to be smokers and women classified as bisexual (OR 3.27, I.97-5.43) and men classified as gay (OR 4.86, 2.28-10.34) were much more likely to report childhood sexual experiences in childhood. Psychological distress was associated with reporting sexual experiences in childhood in men classified as gay and bisexual and women classified as heterosexual. Men classified as bisexual (OR 5.00, I.73-I4.5I) and women classified as bisexual (OR 2.88, I.24- 6.56) were more likely than heterosexuals to report more than one sexual partner in the preceding four weeks. Lesbian, gay and bisexual classified people encountered no more sexual function problems than heterosexuals but men classified as bisexual (OR 2.74, I.12-6.70) were more dissatisfied with their sex lives.

Conclusion: Bisexual and lesbian classified people attending London general practices were more likely to be smokers and gay classified men were at increased risk of psychological distress in comparison to heterosexual classified people. Increased awareness of the sexuality of people seen in primary care can provide opportunities for health promotion. 


\section{Background}

Lesbian, gay and bisexual (LGB) people experience prejudice and discrimination [1] and may have higher rates of anxiety, depression, substance use disorders and suicidal behaviour than heterosexuals [2-5]. Furthermore, despite considerable data on the sexual behaviour of gay men, little is known about the prevalence of sexual dysfunction $[6,7]$ and even less is known about sexual behaviour or dysfunction in lesbians [8] or bisexual people. Most research into the mental health of LGB people has been conducted in North America and many studies have included no comparison groups $[7,9-11]$, recruited nonrandom samples $[6,12]$ or applied unusual definitions of same sex attraction [4]. Few have distinguished gay and lesbian from bisexual people, classifying instead on any degree of same sex attraction [13], usually because of small samples. No previous study has assessed morbidity of gay, lesbian or bisexual people attending their family practitioners.

Although $5 \%$ of the British population is gay or lesbian [14] random sampling often achieves insufficient numbers [15] and/or such low percentages of LGB people that the research process becomes cumbersome and expensive [8]. We recruited people attending family practitioners in order to assess the importance of the sexual orientation of general practices attendees in London to their mental, physical and sexual function.

\section{Methods}

\section{Participants and setting}

Two London (the Camden and Islington and the Enfield and Haringey) local research ethical committees approved the study. We recruited people attending their primary care physicians. 95\% of the people in the UK are registered at general practices that serve as the first point of contact with health services. We approached a group of research general practices in a defined area of north London. None of the practices approached served only a LGB population nor did they advertise or offer special health care to LGB people. We asked consecutive people aged 18 to 75 attending these general practices to participate in the study and in each practice recruited attendees over a $4-8$ week period. Each person approached to participate in the study was given a detailed information sheet on the study procedures. Those consenting to take part were asked to complete a questionnaire in a private setting in the general practice as they waited to see the doctor [16].

\section{Materials}

The questionnaire contained:

1. Standard demographic questions: on age, sex, ethnicity, civil status and current occupation.
2. A question on participants' sexual orientation using Kinsey ratings based on sexual experiences [17]. The respondent was asked to circle any number from 1 to 7 that corresponded to the statement that best described their sexual experiences. These were as follows: 1 entirely heterosexual; 2 largely heterosexual, but with some homosexual experience; 3 largely heterosexual, but considerable homosexual experience; 4 equally heterosexual and homosexual; 5 largely homosexual, but with considerable heterosexual experience; 6 largely homosexual, but with some heterosexual experience and 7 entirely homosexual.

3. Short Form 12 (SF-12): This is a well-validated quality of life questionnaire. We used the 12-item version of this questionnaire that produces separate physical and psychological well-being scores [18].

4. The General Health Questionnaire (GHQ): a measure of current mental health problems. Since its development, it has been extensively used in different settings and cultures [19-23]. The questionnaire was originally developed as a 60 -item instrument but the GHQ-12, a shortened version of the questionnaire, has since been developed. The GHQ-12 is easy to complete and was designed to screen for psychological symptoms in the community. It is not a diagnostic instrument. There is evidence that the GHQ-12 is a consistent and reliable instrument when used in general population samples [24]. The GHQ asks whether the respondent has experienced a particular psychological symptom or behaviour recently. Each item is rated on a four-point scale (less than usual, no more than usual, rather more than usual, or much more than usual).

5. The four-item CAGE questionnaire [25], which is a known screening instrument for possible alcohol misuse. We also included one question on current consumption of cigarettes.

6. Questions about numbers of sexual partners in the preceding four weeks in order to assess risk of sexually transmitted infection.

7. Four screening questions about sexual experiences under the age of 16 years [26]. These concerned a) someone trying to or succeeding in having sexual intercourse with them $b$ ) touching, grabbing, kissing or rubbing up against them in public or private c) taking photographs of them naked or exhibiting parts of their body to them or performing a sex act in their presence and d) perpetrating oral sex or anal intercourse on them.

8 . The brief sexual function questionnaire for men $[27,28]$ and a modified version for women [29]. This questionnaire collected information on sexual activity (i.e. mastur- 
bation, oral sex and sexual intercourse) in the last month and also enabled us to make a sexual dysfunction diagnosis according to the $10^{\text {th }}$ Edition of the International Classification of Diseases [30] (lack/loss of sexual desire, sexual aversion, and dyspareunia in both sexes; arousal and orgasmic disorders and vaginismus in women and erectile and premature and retarded ejaculatory problems in men) and assessed their satisfaction with their sex life.

9. Total family practice consultations over the preceding two years were collected for those participants who allowed us access to their clinical records.

\section{Definition of sexual orientation and physical, psychological and sexual problems}

a) Sexual Orientation: There is still no universal agreement on how to define sexual orientation [31]. Thus we approached our analysis on the assumption that society is more accepting of people who report largely heterosexual, rather than largely homosexual, experiences. Hence we classified people responding to rating 1 on our sexual experiences scale as unequivocally heterosexual. Similarly, we assumed that participants who indicated their experiences had been largely heterosexual or equally heterosexual and homosexual (ratings 2 to 4 ) were primarily identifying with heterosexuality (despite sexual experiences with both sexes) and classified them as bisexual. Finally we assumed that those who indicated that homosexual experiences were a large or entire part of their sexual lives (ratings 5 to 7 ) were likely to be primarily gay or lesbian and were classified accordingly.

b) Poor physical function (quality of life) was defined as those scoring below the $25^{\text {th }}$ centile of the physical function subscale score of the short form 12 questionnaire.

c) Psychological distress The GHQ-12 provides a total score of 36, based on the Likert scoring of 0-1-2-3 or 12 based on a bi-modal (0-0-1-1). We used the latter as it is a more common scoring for psychological symptoms and defined those scoring three or more as likely to have significant psychological distress [20].

d) Problems with alcohol use were defined as those scoring two or more on the CAGE questionnaire.

e) Current smokers were defined as those that admitted to being smokers at the time of interview.

f) Sexual experiences in childhood were defined as unequivocal in participants who gave affirmative answers to at least three of the four screening questions.

g) Sexual function problems: were defined using responses from the brief sexual function questionnaires. In order to meet conservative criteria for a clinical ICD-10 diagnosis (F52.0 to F52.6) the problem needed to be present all or almost all of the time for each diagnosis [16]. However, to account for variation in sexual practices in same sex relationships, we widened the sexual situations in which arousal and orgasmic disorders might occur to include masturbation and oral sex. As previously described [16], we examined any sexual problem reported without requiring that the participant have a sexual partner or report sexual intercourse in the preceding four weeks.

h) Consultations: people were classed as high consulters if their total consultation rate over the previous two years exceeded the $75^{\text {th }}$ centile for the study population.

\section{Analysis}

We examined the data using descriptive statistics. Differences in the demographic, sexual activity, and health outcome data between gay/lesbian, bisexual and heterosexual classified people were examined using the Chi squared statistic for dichotomous and analysis of variance for continuous data. We then explored the influence of age, civil status, ethnicity and current employment on sexual orientation and the primary outcomes of interest. These were physical quality of life (as measured on SF-12) and psychological distress (on the GHQ-12), sexual function, number of sexual partners in the previous month, childhood sexual experiences, CAGE scores, smoking status and consultation rates. Only civil status (married or living with a partner versus the remainder) and ethnicity (white versus non white) were found to be associated both with sexuality and the health outcomes at a significance level of $10 \%$ or less. Thus, we adjusted the analysis of each health factor against our classification of sexual orientation for each of these confounders by fitting logistic models and comparing their fit using the likelihood ratio. We report the $\mathrm{p}$ values to indicate whether the adjustments made a significant difference to the model. People in the heterosexual group were used as the index population on the grounds of their overwhelming majority. Each multivariate analysis was conducted separately for men and women. We analysed the data using SPSS version 10 and Stata version 7 .

\section{Results \\ Response rates and sexuality}

We approached 37 North London general practices situated in areas of high, medium and low socio-economic deprivation. Thirteen practices (35\%) with 55 doctors took part. We found no significant differences in Jarman's underprivileged area scores (that indicate the extent of socio-economic deprivation) between participating and non-participating practices. 1512 (71.6\%) people (1065 women and 447 men) of the 2121 eligible general practice attendees participated but only 771 women and 307 
men consented to access to their clinical records [16]. Twenty women (2.6\%) and $13(4.2 \%)$ men did not answer the question on sexual orientation while $85(8 \%)$ women and $23(5 \%)$ men were classified as bisexual and $38(9 \%)$ men and $26(3 \%)$ women as gay or lesbian (tables 1,2). White male participants were more likely to be classified as gay and white female participants were more likely to be classified as bisexual while those classified as lesbian and gay were most likely to be cohabiting. Men and women classified as bisexual were more sexually active than those classified as gay or heterosexual.

\section{Associations between health, sex and sexual orientation}

There were significant differences between the men classified as gay, bisexual and heterosexual on: mental health problems based on the GHQ-12; having more than one sexual partner in the previous month; reporting sexual experiences in childhood and satisfaction with their sex lives (table 3). Significant differences were observed between women classified as lesbian, bisexual and heterosexual on: current smoking; alcohol misuse based on
CAGE scores; having more than one sexual partner in the previous month and having had sexual experiences in childhood (table 4). There were no differences in consultation rates between the sexual orientation groups for the $71 \%$ of people who allowed us access to their records.

Independent factors associated with health and well-being After adjustment for civil and ethnic status, men classified as bisexual were more likely than those classified as heterosexual to be current smokers (OR 2.48), to report having had more than one sexual partner in the last four weeks (OR 5.0) and to be dissatisfied with their sex lives (OR 2.74) (table 3). Men classified as gay were more likely than those classified as heterosexual (OR 2.52) to score above the threshold of the general health questionnaire indicating current psychological distress and to report sexual experiences in childhood (OR 4.86) (table 3). Women classified as bisexual (OR 2.53) and lesbian (OR 3.13) were more likely to be current smokers than those classified as heterosexual (table 4). Women classified as bisexual were significantly more likely than those classified as

Table I: Demographic details and sexual activity of men

\begin{tabular}{|c|c|c|c|}
\hline & Heterosexual classified $N=373$ & Bisexual classified $\mathrm{N}=23$ & Gay classified N $=38$ \\
\hline Age - Mean (SD)M = 6 & $35.9(12.3)$ & $37.1(12.0)$ & $35.9(12.3)$ \\
\hline \multicolumn{4}{|l|}{ Ethnic status $M=6$} \\
\hline White\# & $268(72.6)$ & $19(82.6)$ & $34(94.4)$ \\
\hline Black & $77(20.9)$ & I (4.4) & $2(5.6)$ \\
\hline South Asian & $8(2.2)$ & $2(8.7)$ & 0 \\
\hline Others & $16(4.4)$ & $\mathrm{I}(4.4)$ & 0 \\
\hline \multicolumn{4}{|l|}{ Occupation $\mathrm{M}=6$} \\
\hline Full/part time work & $252(68.3)$ & $14(60.9)$ & $28(77.8)$ \\
\hline \multicolumn{4}{|l|}{ Civil Status ${ }^{M}=6$} \\
\hline Married & $107(28.7)$ & $7(30.4)$ & I (2.6) \\
\hline Co-habiting & $85(22.8)$ & $6(26.1)$ & $12(31.6)$ \\
\hline \multicolumn{4}{|c|}{ Sexual activity (at least once/last month) } \\
\hline Masturbation* M = 6 & $225(61.1)$ & $19(82.6)$ & $29(78.4)$ \\
\hline Oral Sex ${ }^{M}=3$ & $193(52.0)$ & $13(56.5)$ & $21(56.8)$ \\
\hline Sex Intercourse $* * M=5$ & $263(71.3)$ & $18(78.3)$ & $13(35.1)$ \\
\hline \multicolumn{4}{|l|}{ No. of partners $\mathrm{M}=1$} \\
\hline None & $102(27.4)$ & $5(2 \mid .7)$ & $12(31.6)$ \\
\hline One & $243(65.3)$ & $12(52.2)$ & $18(47.4)$ \\
\hline $2-10 * * *$ & $27(7.3)$ & $6(26.1)$ & $8(21.1)$ \\
\hline
\end{tabular}

$M=$ Number of non responders

$\mathrm{N}=$ column percent,

${ }^{*} p=0.018,{ }^{*} \mathrm{p}=0.0005,{ }^{*} *{ }^{*} \mathrm{p}=0.002$

\# white versus non-white $p=0.011$ 
Table 2: Demographic details and sexual activity of women

\begin{tabular}{|c|c|c|c|}
\hline & Heterosexual classified $\mathrm{N}=934$ & Bisexual classified $\mathrm{N}=85$ & Lesbian classified $\mathrm{N}=26$ \\
\hline Age $-M e a n(S D)^{M}=6$ & $33.1(12.1)$ & $31.4(11.7)$ & $32.7(11.7)$ \\
\hline \multicolumn{4}{|l|}{ Ethnic status ${ }^{M}=6$} \\
\hline White\# & $684(73.6)$ & $72(85.7)$ & $19(73.6)$ \\
\hline Black & $178(19.1)$ & $5(6.0)$ & $6(23.1)$ \\
\hline South Asian & $32(3.4)$ & $2(2.4)$ & 0 \\
\hline Others & $36(3.9)$ & $5(6.0)$ & I (3.9) \\
\hline \multicolumn{4}{|l|}{ Occupation $M=6$} \\
\hline Full/part time work & $523(56.2)$ & $45(54.2)$ & $12(46.2)$ \\
\hline \multicolumn{4}{|l|}{ Civil Status ${ }^{M}=6$} \\
\hline Married & $243(26.0)$ & $6(7.1)$ & $\mathrm{I}(3.8)$ \\
\hline Co-habiting* & $228(24.4)$ & $22(25.9)$ & $15(57.7)$ \\
\hline \multicolumn{4}{|c|}{ Sexual activity (at least once/last month) } \\
\hline Masturbation $* * M=6$ & $293(31.4)$ & $58(69.1)$ & $9(34.6)$ \\
\hline Oral Sex $x^{M}=3$ & $359(38.6)$ & $39(46.4)$ & $12(46.2)$ \\
\hline Sex Intercourse ${ }^{M}=5$ & $626(67.1)$ & $50(59.5)$ & $13(50.0)$ \\
\hline \multicolumn{4}{|l|}{ No. of partners $\mathrm{M}=1$} \\
\hline None & $276(29.7)$ & $27(32.8)$ & $10(38.5)$ \\
\hline One & $243(65.3)$ & $50(58.8)$ & $15(57.7)$ \\
\hline $2-10 * * *$ & $28(3.0)$ & $8(9.4)$ & I (3.9) \\
\hline
\end{tabular}

$M=$ Number of non responders

$\mathrm{N}=$ column percent,

$*_{p}=0.004, *^{*} p=0.0005$,

$* * * 2-10$ partners vs. the rest $p=0.014$

\# white versus non-white $p=0.04$

Table 3: Distribution of health and health behaviours for men

\begin{tabular}{|c|c|c|c|c|}
\hline Variable & $\begin{array}{l}\text { Heterosexual classified } \\
N=373\end{array}$ & $\begin{array}{l}\text { Bisexual classified } \\
N=23\end{array}$ & $\begin{array}{l}\text { Gay classified } \\
N=38\end{array}$ & Chi2, $p$ value \\
\hline Smoking $M=4$ & 144 (39) & $14(61)$ & $19(50)$ & $\begin{array}{l}5.61 \\
P=0.06\end{array}$ \\
\hline SFI 2 physical scale score less than $25^{\text {th }}$ centile ${ }^{M}=23$ & $97(27)$ & $3(16)$ & $13(35)$ & $\begin{array}{l}2.39 \\
P=0.30\end{array}$ \\
\hline GHQ high scorer & $129(35)$ & $6(26)$ & $22(58)$ & $\begin{array}{l}9.19 \\
P=0.01\end{array}$ \\
\hline CAGE high scorer & $119(32)$ & $9(39)$ & $13(34)$ & $\begin{array}{l}0.57 \\
P=0.75\end{array}$ \\
\hline More than I sexual partner in previous month $\mathrm{M}=1$ & $27(7)$ & $6(26)$ & $8(21)$ & $\begin{array}{l}15.48 \\
P=0.00\end{array}$ \\
\hline Any sexual function problem $M=8$ & $167(46)$ & $14(61)$ & $21(55)$ & $\begin{array}{l}3.01 \\
P=0.22\end{array}$ \\
\hline Childhood sexual experiences score 3 or more ${ }^{M}=9$ & $50(14)$ & $6(26)$ & $17(46)$ & $\begin{array}{l}25.91 \\
P=0.00\end{array}$ \\
\hline Dissatisfied with sex life ${ }^{M}=2$ & $218(59)$ & $8(35)$ & $16(42)$ & $\begin{array}{l}8.33 \\
P=0.02\end{array}$ \\
\hline Consultations over $75^{\text {th }}$ centile $M=133$ & $54(21)$ & $3(20)$ & $8(29)$ & $\begin{array}{l}0.89 \\
P=0.64\end{array}$ \\
\hline
\end{tabular}

$M=$ Number of non responders

$\mathrm{N}=$ column per cent

heterosexual (OR 2.73) to record a positive CAGE score 
Table 4: Distribution of health and health behaviours for women

\begin{tabular}{|c|c|c|c|c|}
\hline Variable & $\begin{array}{l}\text { Heterosexual classified } \\
\mathrm{N}=934\end{array}$ & $\begin{array}{l}\text { Bisexual classified } \\
N=85\end{array}$ & $\begin{array}{l}\text { Lesbian classified } \\
N=26\end{array}$ & Chi2, $\mathrm{p}$ value \\
\hline Smoking $M=10$ & $294(32)$ & $48(57)$ & $15(58)$ & $\begin{array}{l}28.27 \\
P=0.00\end{array}$ \\
\hline SFI 2 physical scale score less than $25^{\text {th }}$ centile $\mathrm{M}=20$ & $233(25)$ & $23(28)$ & $6(25)$ & $\begin{array}{l}0.29 \\
P=0.86\end{array}$ \\
\hline GHQ high scorer & $371(40)$ & $40(47)$ & II (42) & $\begin{array}{l}1.78 \\
P=0.41\end{array}$ \\
\hline CAGE high scorer & $164(18)$ & $35(4 I)$ & $8(31)$ & $\begin{array}{l}29.37 \\
P=0.00\end{array}$ \\
\hline More than I sexual partner in previous month $\mathrm{M}=4$ & $28(3)$ & $8(9)$ & I (4) & $\begin{array}{l}9.32 \\
P=0.01\end{array}$ \\
\hline Any sexual function problem $\mathrm{M}=2$ & $567(6 I)$ & $51(60)$ & $14(54)$ & $\begin{array}{l}0.53 \\
P=0.77\end{array}$ \\
\hline Childhood sexual experiences score 3 or more ${ }^{M}=15$ & $112(12)$ & $27(32)$ & $4(15)$ & $\begin{array}{l}25.72 \\
P=0.00\end{array}$ \\
\hline Dissatisfied with sex life ${ }^{M}=10$ & $462(50)$ & $46(55)$ & $16(62)$ & $\begin{array}{l}1.98 \\
P=0.37\end{array}$ \\
\hline Consultations over $75^{\text {th }}$ centile $\mathrm{M}=287$ & $186(27)$ & $13(22)$ & $5(25)$ & $\begin{array}{l}0.83 \\
P=0.66\end{array}$ \\
\hline
\end{tabular}

$M=$ Number of non responders

$\mathrm{N}=$ column per cent

indicating possible alcohol misuse, to have had more than one sexual partner in the last four weeks (OR 2.85) and to report sexual experiences in childhood (OR 3.27) (table 4).

\section{Sexual experiences in childhood and current pyshcolgical distress}

Sexual experiences in childhood and high GHQ-12 scores appeared to occur together in gay and bisexual classified men (table 3) and so we explored their association further. To do this we compared heterosexual classified participants with gay and bisexual classified participants combined. This revealed associations only for gay and bisexual men and heterosexual women. Thirty-six per cent $(18 / 50)$ of heterosexual classified men who reported childhood sexual experiences had GHQ-12 scores over 2 compared to $34 \%(107 / 315)$ of such men who did not report childhood experiences. Similarly, 48\% (15/31) of lesbian and bisexual classified women who reported childhood experiences had GHQ-12 scores over 2 compared to $44 \%$ (35/79) of such women who did not report childhood experiences. In contrast, $65 \%$ (15/23) of gay and bisexual classified men who reported childhood sexual experiences had high GHQ-12 scores compared to $45 \%(\mathrm{n}=9 / 20)$ who did not report childhood experiences (Chi2 $=6.16, P=0.013)$. And similarly, 51\% (57/112) of heterosexual classified women who reported childhood sexual experiences had high GHQ-12 scores compared to $38 \%(306 / 808)$ who did not report such experiences $($ Chi2 $=6.98, \mathrm{P}=0.008)$.

\section{Discussion Main findings}

In comparison to their heterosexuals counterparts: 1) women classified as lesbian were more likely to be smokers; 2) men classified as gay had higher levels of psychological symptoms and were more likely to report childhood sexual experiences; 3) women classified as bisexual were more likely to misuse alcohol, to be smokers, to report more than one sexual partner in the preceding four weeks and to report childhood sexual experiences; 4) men classified as bisexual were more likely to report more than one sexual partner in the preceding four weeks and to be dissatisfied with their sex lives. Reporting childhood sexual experiences was associated with adult psychological distress in gay and bisexual classified men and heterosexual classified women.

\section{Strengths and limitations of the study}

To our knowledge this is the first European study in which the mental and physical health of people of a range of sexual orientation, attending family practitioners has been compared. Consecutive recruitment meant that our samples of gay and bisexual people were comparatively small and led to relative uncertainty in our estimates of odds ratios. In keeping with the higher rate of attendance of women compared with men in UK general practice [32], in this study we recruited just over twice the numbers of women rather than men. We did not find any differences in the consultation rates of attendees classified as gay, lesbian, bisexual or heterosexual. Nevertheless, it is still possible that differences in help seeking behaviour between 
men and women and between people classified as gay, lesbian and bisexual would make it difficult to generalise our finding to either sex or people classified as gay, lesbian or bisexual as a whole. Recruiting general practice attendees also means that the prevalence of physical or psychological difficulties may have been higher than in the general population, given that participants would often have been seeking help for medical or social problems. Our results are hence limited to the people recruited to our study and may not represent that of the UK or Europe as a whole.

We used a definition of sexuality based on criteria developed for this study. There is little consensus on how to measure sexual orientation. Several issues should be considered. Firstly, sexual responsiveness to others of the same sex, like most human traits is believed to be continuously distributed in the population $[17,33]$. Secondly, it may be incorrect to presume that such traits are stable within each person over time [34]. Thirdly, conflating any same-sex experiences with a categorization of the person as homosexual may present limitations when defining sexuality. Lastly, defining sexuality solely on the basis of sexual experience [17] may exclude people who fantasize about sex with others of the same sex but never have sexual contact [35]. Modern concepts of sexual orientation consider personal identification, sexual behaviour and sexual fantasy [36]. Few studies, however, utilise all these three definitions in arriving at a composite categorization of sexuality. One widely established definition is a person "with an orientation towards people of the same gender in sexual behaviour, affection, or attraction, and/or selfidentity as gay/lesbian or bisexual" [37]. Using these types of definition, there is evidence that at least five per cent of people in western countries are gay or bisexual [14,3438]. In our study classification of sexuality was limited by the Kinsey classification for which no time frame was applied. Moreover the classification of gay, bisexual and heterosexual as applied to people recruited in our study has not been previously used in similar population and it is possible that a different classification using the Kinsey scale might have yielded different results. Nevertheless, based on the categorization of sexual orientation used in this study, prevalence estimates of gay, lesbian and bisexual people in our sample closely matched that reported from London in a larger UK wide population survey [14].

There were also limitations in the way some data were collected. We assessed sexual behaviour using standardised questionnaires that were not explicit in their definition of sexual intercourse [27-29]. Many people (gay or straight) regard sexual intercourse differently and do not always realise that it means penetrative (vaginal or anal) sex. Furthermore, for gay men receptive anal intercourse can be regarded as "sexual intercourse" more often than insertive anal intercourse. At first sight our figures for sexual intercourse in gay classified men may seem low and those for lesbian classified woman high. However, most of our evidence on the prevalence of anal intercourse in gay men arises from particular populations, such as younger age groups, men attending clubs and bars or those living in gay neighbourhoods. Studies using diary records show that reported rates of intercourse depend on whether not the man has a regular same-sex partner and if so whether the relationship is open or closed. Those in closed relationships and those without regular partners may have relatively low rates of penile-anal intercourse [39]. Given the wide age range in our sample and the fact that these men were not selected on any sexual risk grounds, it is not surprising that only $35 \%$ of gay men reported sexual intercourse in the preceding 4 weeks. Moreover, vaginal penetrative practices using sex toys and fingers or hands are commonly reported by lesbian and bisexual women $[40,41]$.

\section{Mental health of gay men and lesbians}

Our finding of higher rates of common psychological symptoms of depression and anxiety, in gay classified men accords with those of a recent study of the mental health of gay men and lesbians in England and Wales in which a large sample was recruited by snowball sampling [12]. There are a number of reasons why gay people may be more likely to report psychological difficulties, which include difficulties growing up in a world orientated to heterosexual norms and values and the negative influence of social stigma against homosexuality. In addition, the gay commercial world in which some men and women may participate to find partners and friends may make misuse of alcohol and cigarettes more likely $[3,12]$. The former in particular can have adverse effects on mental well-being. Finally, our results add to evidence that sexual experiences in childhood in men classified as gay or bisexual may play a role in adult psychological adjustment $[42,43]$. Why this is not the case in lesbian and bisexual classified women requires further exploration.

\section{Mental health of bisexual people}

Much less is known about how bisexual, as opposed to gay people, accept their sexual orientation or whether the possibility of having partners of either sex introduces difficulties. Although there is anecdotal evidence that bisexuality is regarded negatively by gay and lesbian political and social groups, it may present to people living in a predominantly heterosexual world as being of a more acceptable social status than that of a gay or lesbian identity. We found, however, little difference in psychological distress between people classified as bisexual and heterosexual, despite the finding that women classified as bisexual reported more sexual experiences in childhood than heterosexual classified women. This finding has also been 
Table 5: Health comparisons in heterosexual, bisexual and gay classified men

\begin{tabular}{|c|c|c|c|c|c|}
\hline Variable & Predictor & number & Odds ratio for increased risk & LR chi2 & $\mathrm{P}$-value \\
\hline \multirow[t]{6}{*}{ Smoking } & Bisexual & 424 & $2.47(1.04,5.86)$ & & \\
\hline & Gay & & I.42 (0.7I, 2.83) & & \\
\hline & Bisexual & & $2.48(1.05,5.90)$ & & \\
\hline & Gay & & $1.36(0.67,2.73)$ & & \\
\hline & White & & $1.06(0.67,1.67)$ & & \\
\hline & Civil status\# & & $0.81(0.55,1.20)$ & 1.15 & 0.56 \\
\hline \multirow[t]{6}{*}{ SFI 2 physical scale score less than $25^{\text {th }}$ centile } & Bisexual* & 405 & $0.49(0.14,1.75)$ & & \\
\hline & Gay & & $1.57(0.76,3.24)$ & & \\
\hline & Bisexual & & $0.49(0.14,1.72)$ & & \\
\hline & Gay & & $1.49(0.7 \mathrm{I}, 3.1 \mathrm{I})$ & & \\
\hline & White & & $1.21(0.72,2.04)$ & & \\
\hline & Civil status & & $0.93(0.60,1.44)$ & 0.63 & 0.730 \\
\hline \multirow[t]{6}{*}{ GHQ high scorer } & Bisexual & 405 & $0.66(0.25,1.71)$ & & \\
\hline & Gay & & $2.60(1.30,5.23)$ & & \\
\hline & Bisexual & & $0.66(0.26,1.73)$ & & \\
\hline & Gay & & $2.52(1.25,5.11)$ & & \\
\hline & White & & $0.97(0.61,1.55)$ & & \\
\hline & Civil status & & $0.78(0.52,1.15)$ & 1.56 & 0.46 \\
\hline \multirow[t]{6}{*}{ CAGE high scorer } & Bisexual & 428 & $1.38(0.58,3.30)$ & & \\
\hline & Gay & & $0.95(0.45,1.99)$ & & \\
\hline & Bisexual & & $1.35(0.57,3.23)$ & & \\
\hline & Gay & & $0.85(0.40,1.80)$ & & \\
\hline & White & & I.46 $(0.89,2.40)$ & & \\
\hline & Civil status & & $0.80(0.53,1.21)$ & 3.39 & 0.18 \\
\hline \multirow[t]{6}{*}{ More than I sexual partner in previous month } & Bisexual & 427 & $4.45(1.62,12.24)$ & & \\
\hline & Gay & & $3.05(1.22,7.60)$ & & \\
\hline & Bisexual & & $5.00(1.73,14.51)$ & & \\
\hline & Gay & & $2.35(0.91,6.06)$ & & \\
\hline & White & & $\mathrm{I} .74(0.69,4.4 \mathrm{I})$ & & \\
\hline & Civil status & & $0.24(0.11,0.53)$ & 16.22 & 0.0003 \\
\hline \multirow[t]{6}{*}{ Any sexual function problem } & Bisexual & 421 & $1.82(0.77,4.30)$ & & \\
\hline & Gay & & $1.46(0.73,2.91)$ & & \\
\hline & Bisexual & & $\mathrm{I} .86(0.78,4.4 \mathrm{I})$ & & \\
\hline & Gay & & I.47 $(0.73,2.97)$ & & \\
\hline & White & & $0.86(0.55,1.35)$ & & \\
\hline & Civil status & & $0.86(0.59,1.27)$ & 0.97 & 0.62 \\
\hline \multirow{6}{*}{$\begin{array}{l}\text { Childhood sexual experiences score of } 3 \text { or } \\
\text { more }\end{array}$} & Bisexual & 419 & $2.25(0.84,5.97)$ & & \\
\hline & Gay & & $4.77(2.29,9.95)$ & & \\
\hline & Bisexual & & $2.17(0.81,5.81)$ & & \\
\hline & Gay & & $4.86(2.28,10.34)$ & & \\
\hline & White & & I.3I $(0.67,2.54)$ & & \\
\hline & Civil status & & $1.46(0.85,2.50)$ & 2.57 & 0.28 \\
\hline \multirow[t]{6}{*}{ Dissatisfied with sex life } & Bisexual & 426 & $2.62(1.08,6.34)$ & & \\
\hline & Gay & & $1.75(0.88,3.48)$ & & \\
\hline & Bisexual & & $2.74(1.12,6.70)$ & & \\
\hline & Gay & & $1.56(0.77,3.15)$ & & \\
\hline & White & & I.II $(0.70,1.76)$ & & \\
\hline & Civil status & & $0.52(0.35,0.77)$ & 11.2 & 0.004 \\
\hline Consultations over $75^{\text {th }}$ centile & Bisexual & 300 & $0.94(0.26,3.44)$ & & \\
\hline
\end{tabular}


Table 5: Health comparisons in heterosexual, bisexual and gay classified men (Continued)

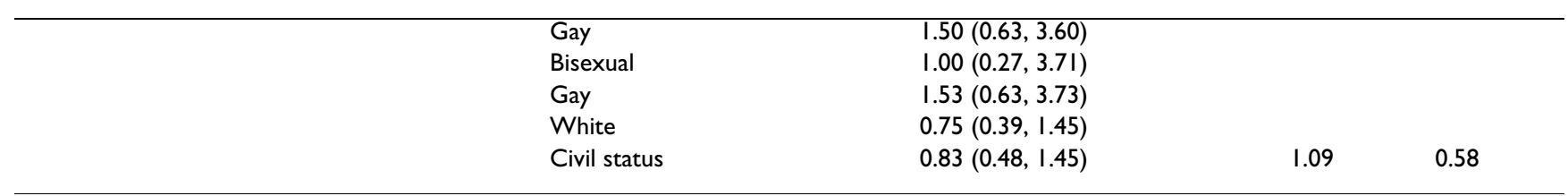

Odd Ratio below the line in each row are adjusted for civil and ethnic status

$\mathrm{LR}=$ Likelihood ratio * Heterosexual used as reference category OR I.0 \# married/cohabiting

reported in a population-based study in North American, where bisexual (and lesbian) women had higher lifetime rates of substance misuse and coerced sex than heterosexual women [44].

\section{Physical and sexual health}

There were no differences between people classified as gay and heterosexual in terms of physical functioning based on a quality of life measure. People classified as bisexual on the other hand were more likely to be smokers raising concern about smoking related diseases such as cancers, cardiovascular diseases and chronic obstructive airway diseases. There is now good data on smoking among gay, lesbian and bisexual people. Data from population based health surveys and random student population samples in North America have suggested high rates of smoking in LGB people [38]. Men and women classified as bisexual were also more likely than heterosexuals to report contact with two or more sexual partners in the preceding month, potentially increasing their likelihood of acquiring sexually transmitted infections. For women classified as bisexual this combination with alcohol misuse could also place them at a greater risk of sexually transmitted infections. There is good evidence that risky sexual behaviour is increasing among men and women but comparative data on sexual behaviour of different sexual orientations has to our knowledge not been previously reported [14].

\section{Family practice}

There is varying evidence on the use of family practice by lesbian, gay and bisexual people. We have previously reported that LGB people consult general practitioners for emotional reasons more often than heterosexuals [12]. However, other research in the UK suggests that LGB people may avoid primary medical care [49] and those that do attend may not reveal their sexual orientation [50]. Awareness of a patient's sexual orientation may alert the family practitioner to potential difficulties, particularly with regard to alcohol misuse and smoking and to some extent sexual behaviour. There is a clear need for awareness on the part of family practitioners and openness on the part of patients about sexual orientation. This would allow practice staff adequate opportunities to monitor the smoking status, alcohol use, mental health, current numbers of sexual contacts and childhood sexual experiences in people of range of sexual orientation attending family practice. People at risk could then be offered early interventions to minimise their chances of developing more advanced illnesses.

\section{Conclusion}

Bisexual and lesbian classified people attending London general practices were more likely to be smokers and gay classified men were at increased risk of psychological distress when compared to people classified as heterosexual. Sexual experiences in childhood were associated with current psychological distress in heterosexual classified women and in gay and bisexual classified men but this was not the case for non-heterosexual women or heterosexual classified men. Increased awareness of the sexuality of people seen in primary care can provide opportunities for health promotion.

\section{Competing interests}

The author(s) declare that they have no competing interests.

\section{Authors' contributions}

$\mathrm{MK}$ and IN conceived the idea, obtained funding for the study, analysed the data and wrote the paper. MK and IN are guarantors for the study. 
Table 6: Health comparisons in heterosexual, bisexual and lesbian classified women

\begin{tabular}{|c|c|c|c|c|c|}
\hline Variable & Variable & number & Odds ratio for increased risk & LR chi2 & P-value \\
\hline \multirow[t]{6}{*}{ Smoking } & Bisexual & 1030 & $2.85(1.81,4.49)$ & & \\
\hline & Lesbian & & $2.92(1.32,6.43)$ & & \\
\hline & Bisexual & & $2.53(1.60,4.00)$ & & \\
\hline & Lesbian & & $3.13(1.41,6.97)$ & & \\
\hline & White & & $1.63(1.19,2.24)$ & & \\
\hline & Civil status & & $0.64(0.49,0.83)$ & 19.02 & 0.0001 \\
\hline \multirow[t]{6}{*}{ SFI 2 physical scale score less than $25^{\text {th }}$ centile } & Bisexual & 1022 & $1.14(0.69,1.89)$ & & \\
\hline & Lesbian & & $0.98(0.38,2.45)$ & & \\
\hline & Bisexual & & $1.07(0.64,1.78)$ & & \\
\hline & Lesbian & & $0.98(0.38,2.50)$ & & \\
\hline & White & & $1.53(1.09,2.16)$ & & \\
\hline & Civil status & & $0.91(0.68,1.21)$ & 6.47 & 0.039 \\
\hline \multirow[t]{6}{*}{ GHQ high scorer } & Bisexual & 1039 & $1.33(0.85,2.08)$ & & \\
\hline & Lesbian & & $\mathrm{I} .12(0.5 \mathrm{I}, 2.47)$ & & \\
\hline & Bisexual & & $1.24(0.79,1.95)$ & & \\
\hline & Lesbian & & $1.15(0.52,2.53)$ & & \\
\hline & White & & $1.26(0.95,1.69)$ & & \\
\hline & Civil status & & $0.81(0.63,1.04)$ & 4.95 & 0.08 \\
\hline \multirow{6}{*}{ CAGE high scorer } & Bisexual & 1039 & $3.17(1.99,5.06)$ & & \\
\hline & Lesbian & & $2.07(0.89,4.85)$ & & \\
\hline & Bisexual & & $2.73(1.70,4.40)$ & & \\
\hline & Lesbian & & $2.23(0.94,5.30)$ & & \\
\hline & White & & $2.35(1.54,3.59)$ & & \\
\hline & Civil status & & $0.61(0.45,0.85)$ & 24.95 & 0.0000 \\
\hline \multirow{6}{*}{ More than I sexual partner in previous month } & Bisexual & 1035 & $3.37(1.48,7.65)$ & & \\
\hline & Lesbian & & $1.28(0.17,9.79)$ & & \\
\hline & Bisexual & & $2.85(1.24,6.56)$ & & \\
\hline & Lesbian & & $1.40(0.18,10.80)$ & & \\
\hline & White & & $1.48(0.64,3.45)$ & & \\
\hline & Civil status & & $0.44(0.21,0.90)$ & 5.96 & 0.05 \\
\hline \multirow[t]{6}{*}{ Any sexual function problem } & Bisexual & 1037 & $0.95(0.60,1.49)$ & & \\
\hline & Lesbian & & $0.75(0.34,1.64)$ & & \\
\hline & Bisexual & & $0.98(0.62 \quad$ I. .55$)$ & & \\
\hline & Lesbian & & $0.72(0.33,1.59)$ & & \\
\hline & White & & $1.16(0.87,1.54)$ & & \\
\hline & Civil status & & $1.36(1.06,1.75)$ & 7.26 & 0.03 \\
\hline \multirow[t]{6}{*}{ Childhood sexual experiences score of 3 or more } & Bisexual & 1025 & $3.43(2.08,5.56)$ & & \\
\hline & Lesbian & & $1.32(0.45,3.89)$ & & \\
\hline & Bisexual & & $3.27(1.97,5.43)$ & & \\
\hline & Lesbian & & $1.32(0.44,3.92)$ & & \\
\hline & White & & $1.46(0.93,2.30)$ & & \\
\hline & Civil status & & $0.97(0.67,1.39)$ & 2.90 & 0.23 \\
\hline \multirow[t]{6}{*}{ Dissatisfied with sex life } & Bisexual & 1030 & $1.22(0.78,1.90)$ & & \\
\hline & Lesbian & & $1.61(0.72,3.58)$ & & \\
\hline & Bisexual & & $1.08(0.68,1.71)$ & & \\
\hline & Lesbian & & $1.76(0.78,3.98)$ & & \\
\hline & White & & $0.97(0.73,1.29)$ & & \\
\hline & Civil status & & $0.48(0.38,0.62)$ & 33.04 & 0.0000 \\
\hline \multirow[t]{2}{*}{ Consultations over $75^{\text {th }}$ centile } & Bisexual & 755 & $0.75(0.40,1.42)$ & & \\
\hline & Lesbian & & $0.88(0.32,2.47)$ & & \\
\hline
\end{tabular}


Table 6: Health comparisons in heterosexual, bisexual and lesbian classified women (Continued)

$\begin{array}{ll}\text { Bisexual } & 0.77(0.40,1.47) \\ \text { Lesbian } & 0.87(0.31,2.47) \\ \text { White } & 0.98(0.66,1.45) \\ \text { Civil status } & 1.16(0.84,1.61)\end{array}$

$0.87(0.31,2.47)$

$1.16(0.84,1.61)$
0.81

0.67

Odd ratios below the line in each row are adjusted for civil and ethnic status

$\mathrm{LR}=$ likelihood ratio Heterosexual used as reference category OR I.0 \# married/cohabiting

\section{Acknowledgements}

The study was funded by a Health Service Research Project Grant provided by The Wellcome Trust, Grant reference 991026.

The North and Central Thames Research Network (NoCTeN) and the Camden and Islington Mental Health and Social Care Trust provided support for the study.

We wish to thank the family practitioners and the patients; Dr Josephine Woolf for her collaboration in obtaining funding; Ms Alice Gladwin, Ms Monique Cloherty and Ms Üta Drescher for their assistance in data collection and Dr Petra Boynton for managing the data collection and the data entry.

\section{References}

I. Mays VM, Cochran SD: Mental health correlates of perceived discrimination among lesbian, gay and bisexual adults in the United States. American Journal of Public Health 2000, 91:1869-1976

2. Hershberger SL, D'Augelli AR: The impact of victimisation on the mental health and suicidality of lesbian, gay, and bisexual youths. Developmental Psychology 1995, 67:65-74.

3. Cochran SD, Mays VM: Lifetime prevalence of suicide symptoms and affective disorders among men reporting same-sex sexual partners: results from NIHANES III. American Journal of Public Health 2000, 90:573-578.

4. Fergusson DM, Horwood LJ, Beautrais AL: Is sexual orientation related to mental health problems and suicidality in young people? Archives General Psychiatry 1999, 56:876-880.

5. Lock J, Steiner H: Gay, lesbian and bisexual youth risks for emotional, physical and social problems: results from community-based survey. J Am Acad Child \& Adolescent Psychiatry 1999 38:297-304.

6. Moreira ED, Naijar Abdo CH, Barreto Torres E, Lisboa-Lobo CF, Saraiva Fittipaldi JA: Prevalence and correlates of erectile dysfunction: results of the Brazilian study of sexual behaviour. Urology 200I, 58:583-588.

7. Sandfort TGM, de Keizer M: Sexual problems in gay men: an overview of empirical research. Annual Review of Sex Research 200I, 12:93-120

8. Ventegodt S: Sex and quality of life in Denmark. Archives of Sexual behaviour 1998, 27:295-307.

9. Pillard R: Sexual orientation and mental disorder. Psychiatric Annals 1998, 18:51-56.

10. Atkinson JH, Grant I, Kennedy CJ, Richman DD, Spector SA McCutchan JA: Prevalence of psychiatric disorders among men infected with human immunodeficiency virus. A controlled study. Arch Gen Psychiatry 1988, 45:89-64.

II. Coyle A: A study of psychological well-being among gay men using the GHQ-30. British Journal of Clinical Psychology 1993, 32:218-220.

12. King M, McKeown E, Warner J, Ramsay A, Johnson K, Cort C, Wright L, Blizard R, Davidson O: Mental health and quality of life of gay men and lesbians in England and Wales: a controlled, crosssectional study. British Journal of Psychiatry 2003, I 83:552-558.

13. Skegg K, Shyamala N, Dickson N, Paul C, Williams S: Sexual orientation and self-harm in men and women. American Journal of Psychiatry 2003, 160:54I-546.

14. Johnson A, Mercer C, Erens B, Copas A, McManus S, Wellings K, Fenton K, Korovessis C, Macdowall W, Nanchalal K, Purdon S, Field J: Sexual behaviour in Britain: partnerships, practice and HIV risky behaviours. The Lancet 200I, 358:1835-42.
15. Gilman SE, Cochran S, Mays V, Hughes M, Ostrow D, Kessler RC: Risk of psychiatric disorders among individuals reporting same-sex sexual partners in the national co-morbidity survey. American Journal of Public Health 2001, 91:933-939.

16. Nazareth I, Boynton P, King M: Problems with sexual function in people attending London general practitioners: a cross sectional study. British Medical Journal 2003, 327:423-426.

17. Kinsey AC, Pomeroy WB, Martin CE: Sexual behaviour in the human male. Saunders, Philadelphia; 1948.

18. Ware JE, Kosinski M, Keller SD: A I 2-item short-form health survey construction of scales and preliminary tests of reliability and validity. Medical Care 1996, 34:220-233.

19. Goldberg DP, Blackwell B: Psychiatric illness in general practice. A detailed study using a new method of case identification. British Medical Journal 1970, I:439-443.

20. Goldberg D, Williams P: A user's guide to the General Health questionnaire. Windsor, UK: NFER-Nelson; 1988.

21. Schmitz N, Kruse J, Tress W: Psychometric properties of the General Health Questionnaire (GHQ)- I 2) in a German primary care. Acta Psychiatrica Scandinavica 1999, 100:462-468.

22. Jacob KS, Bhugra D, Mann AH: The validation of the I2-item General Health questionnaire in ethnic Indian women living in the United Kingdom. Psychological Medicine 1997 27:1215-1217.

23. Donath S: The validity of the I2-item General Health Questionnaire in Australia: a comparison between three scoring methods. Aust N Z Journal of Psychiatry 200I, 35:23I-235.

24. Pevalin DJ: Multiple applications of the GHQ- 2 in a general population sample: an investigation of long-term retest effects. Soc Psychiatry Psychiatric Epidemiology 2000, 35:508-5 I 2.

25. Ewing JA: Detecting alcoholism: the CAGE questionnaire. Journal of the American Medical Association 1984, 252:1905-1907.

26. Finkelhor D: Child sexual abuse. In Violence in America - a public health approach Edited by: Rosenberg ML, Fenley MA. Oxford University Press, New York; 1991:79-94.

27. Reynolds CF, Frank E, Thase ME, Houck PR, Jennings JR, Howell JR, Scott OL, Kupfer DJ: Assessment of sexual function in depressed, impotent, and healthy men: factor analysis of a brief sexual function questionnaire for men. Psychiatry Research 1987, 24:23I-250.

28. Daker-White G: Reliable and valid self-report outcome measures in sexual dysfunction: a systematic review. Archives of Sexual Behaviour 2002, 3 I: 197-209.

29. Taylor JF, Rosen RC, Leiblum SR: Self report assessment of female sexual function. Archives of Sexual Behaviour 1994, 23:627-643.

30. World Health Organisation: International statistical classification of disease and related health problems. $10^{\text {th }}$ revision. World Health Organisation, Geneva 1992.

31. Hooker E, Ziemba-Davis M, McWhirter DP, Sanders SA, Reinisch JM, eds: Homosexuality/Heterosexuality. Concepts of Sexual Orientation. OUP, New York; 1900:399-40I.

32. Office of Population Censuses and Surveys: OPCS Monitor MB5 94/I. Morbidity Statistics from General Practice 199//2 (MSGP4). London: HMSO; 1994

33. McConaghy $\mathrm{N}$, Blaszczynski $\mathrm{A}$ : Initial stages of validation by penile volume assessment that sexual orientation is distributed dimensionally. Comp Psychiatry 1991, 32:52-58.

34. Michaels S: The prevalence of homosexuality in the United States. In Cabaj R P, Stein T S. (eds) Textbook of Homosexuality and Mental Health. American Psychiatric Press, 1996:43-63.

35. Gilman SE, Cochran SD, Mays VM, Hughes M, Ostrow D, Kessler D: Risk of psychiatric disorders among individuals reporting 
same-sex sexual partners in the national comorbidity survey. American Journal of Public Health 2001, 91:933-939.

36. McWhirter DP, Sanders SA, Reinisch JM: Homosexuality/Heterosexuality. New York: Oxford University Press; 1990.

37. Dean L, Meyer IH, Robinson K, Sell R, Sember R, Silenzio V, Bowen D, Bradford J, Rothblum E, Scout D, White J, Dunn P, Lawrence A Wolfe $D$, Xavier J: Lesbian, gay, bisexual and transgender health: findings and concerns. Journal of Gay Lesbian Medical Association 2000, 4: I0I-I5I.

38. Sell RL, Wells JA, Wypij D: The prevalence of homosexual behaviour and attraction in the United States, the United Kingdom and France: results of national population-based samples. Archives of Sexual Behaviour 1995, 24:235-248.

39. Coxon AP, Coxon NH, Weatherburn P, Hunt AJ, Hickson F, Davies PM, McManus T]: Sex role separation in sexual diaries of homosexual men. AIDS 1993, 7:877-882.

40. Bailey JV, Farquhar C, Owen C, Whittaker D: Sexual behaviour of lesbians and bisexual women. Sexually Transmitted Infections 2003, 79:147-I50.

4I. Marrazzo JM, Coffey P, Elliott MN: Sexual practices, risk perception and knowledge of sexually transmitted disease risk among lesbian and bisexual women. Perspectives in Sexual Reproductive Health 2005, 37:6-12.

42. Doll LS, Joy D, Bartholow BN, Harrison JS, Bolan G, Douglas JM, Saltzman LE, Moss PM, Delgado W: Self-reported childhood and adolescent sexual abuse among adult homosexual bisexual men. Child Abuse and Neglect 1992, 16:855-864.

43. Lenderking WR, Wold C, Mayer KH, Goldstein R, Losina E, Seage GR: Childhood sexual abuse among homosexual men. Prevalence and association with unsafe sex. Journal of General Internal Medicine 1997, I2:250-253.

44. Scheer S, Parks CA, McFarland W, Page SK, Delgado V, Ruiz JD, Molitor F, Klausner JD: Self-reported sexual identity sexual behaviour and health risks: examples from a populationbased survey of young women. Journal of Lesbian Studies 2003, 7:69-83.

45. Tang H, Greenwood G, Cowling D, Lloyd J, Roeseler A, Bal D: Cigarettes smoking among lesbian, gays and bisexual: How serious a problem? Cancer Causes and Control 2004, I 5:797-803.

46. Burgard S, Cochran S, Mays V: Alcohol and tobacco use patterns among heterosexually and homosexually experience California women. Drugs and Alcohol Dependence 2004, 77:61-70.

47. Eisenberg M, Wechsler H: Substance use behaviours among college students with same sex and opposite sex experience: results from a national study. Addictive Behaviours 2003, 28:899-9/3.

48. Ryan H, Pascale MW, Easton A, Pederson L, Greenwood G: Smoking among lesbian, gays and bisexuals - a review of the literature. American Journal of Preventive Medicine 200I, 21 : I 42-49.

49. Harrison AE, Silenzio VM: Comprehensive care for lesbian and gay patients and families. Primary Care 1996, 23:3I-46.

50. Fitzpatrick R, Dawson J, Boulton M, McLean J, Hart G, Brooks M: Perceptions of general practice among homosexual men. British Journal of General Practice 1994, 44:80-82.

\section{Pre-publication history}

The pre-publication history for this paper can be accessed here:

http://www.biomedcentral.com/1471-2458/6/127/pre pub
Publish with Bio Med Central and every scientist can read your work free of charge

"BioMed Central will be the most significant development for disseminating the results of biomedical research in our lifetime. "

Sir Paul Nurse, Cancer Research UK

Your research papers will be:

- available free of charge to the entire biomedical community

- peer reviewed and published immediately upon acceptance

- cited in PubMed and archived on PubMed Central

- yours - you keep the copyright
BioMedcentral 